\title{
Sprayed Zno Thin Film; Structural, Morphological, Optical and Electrical Studies
}

\author{
Fawzy A. Mahmoud ${ }^{1}$, M.Boshta ${ }^{1}$, M.B.S. Osman', \\ and Hagar Mohamed ${ }^{*}$ \\ ${ }^{1}$ Solid State Physics Dept., National Research Center, P.O. 12311, \\ Dokki, Giza, Egypt \\ ${ }^{2}$ Physics Department, Faculty of Girls, Ain Shams University, \\ Heliopolis, Cairo, Egypt \\ Email: hagar_electronics@hotmail.com
}

\begin{abstract}
Zinc oxide $(\mathrm{ZnO})$ thin films have been deposited at various deposition temperatures ranged from $350^{\circ} \mathrm{C}$ to $500^{\circ} \mathrm{C}$ and constant spray time by spray pyrolysis technique onto glass substrates. X-ray diffraction (XRD) results showed that the all films are polycrystalline with hexagonal wurtzite structure and exhibite (002) preferential orientation. All films exhibit high transmittance up to $90 \%$ in the visible region. The value of prepared $\mathrm{ZnO}$ films resistivity decreased with increasing the deposition temperature. Sprayed $\mathrm{ZnO}$ film deposited at $450^{\circ} \mathrm{C}$ shows the best opto-electronic properties.
\end{abstract}

\section{Introduction}

Thin films of non-stoichiometric and doped metallic oxides of $\mathrm{ZnO}$, $\mathrm{SnO} 2$ and $\mathrm{ZnO}: \mathrm{Al}$ etc. had attracted a large attention because of their electrical and optical properties making them suitable for application in different kinds of optoelectronic devices [1]. Among these materials, $\mathrm{ZnO}$ thin films have recently gained much attention due to its advantages over other oxide thin films like ITO, SnO2, etc. These advantages include non- toxicity, low cost, high electrical conductivity and transparency [2], $\mathrm{ZnO}$ is an n-type semiconductor with an optical band gap about $3.3 \mathrm{eV}$ consequently, it exhibits high transmittance in the visible region [3]. Various deposition techniques have been widely used to produce $\mathrm{ZnO}$ thin films. However, seeking the most reliable and economic deposition technique is the main goal. The most intensively studied techniques include, R F magnetron sputtering [4], chemical vapor deposition (CVD) [5], sol-gel method [6], thermal evaporation [7] and spray pyrolysis $[8,9]$. Among these techniques, spray pyrolysis is one of the most widely used methods. Spray pyrolysis has been developed as a powerful tool to prepare various kinds of thin films such as metal oxides, superconducting materials, and 
nanophase materials. In comparison with other chemical deposition techniques, spray pyrolysis has several advantages such as high purity, excellent control of chemical uniformity, and stoichiometry in multi-component system. The other advantage of the spray pyrolysis method is that it can be adapted easily for production of large-area films simplicity, safety, the low cost of the apparatus and the raw materials [10]. In this paper we investigate the effects of deposition temperature on the structural, morphological, optical and electrical properties of sprayed $\mathrm{ZnO}$ thin films.

\section{Experimental Details}

Spray pyrolysis is a simple technique, in which the precursor solution is pulverized by means of the solution that arrives to the substrate in the form of very fine droplets. The constituents react to form a chemical compound onto the substrate. The chemical reactants are selected in such a way that the products other than the desired compound are volatile at the deposition temperature. An aqueous solution of zinc acetate dehydrated $\left(\mathrm{Zn}\left(\mathrm{CH}_{3} \mathrm{COO}\right)_{2}\right.$. $\left.2 \mathrm{H}_{2} \mathrm{O}\right)$ was used to deposit $\mathrm{ZnO}$ thin films. At first, aqueous solution $(0.3 \mathrm{M})$ of this salt were prepared in a mixture of deionized water and ethanol (1:3 volume proportions). The solution was sprayed onto glass for various deposition temperature ranges from $350^{\circ} \mathrm{C}$ to $500^{\circ} \mathrm{C}$. The compressed air was used as atomization gas. Spray time, distance between nozzle and substrate, pressure of the carrier gas, and spray rate were optimized to obtain good quality thin films. The glass substrates were ultrasonically cleaned in acetone, ethanol and distilled water. The X-ray diffraction (XRD) of prepared films was obtained by Philips diffractometer model (PW3040) using K $\alpha 1$ radiation $\left(\lambda=1.54 \mathrm{~A}^{\circ}\right)$ in range $2 \theta=\left(30^{\circ}-70^{\circ}\right)$. The surface morphology of the films was examined the Scan Electronic Microscope (SEM) by FEI Quantum FEG 250. The thickness of films is measured using Dektak 150 Stylus profilmeter. The optical properties were obtained by UV/Vis/NIR spectrophotometer model Jasco-670 in the wavelength range $200-2500 \mathrm{~nm}$. The electric properties of deposit films were characterized by Hall Effect measurement Lake Shore model -7700A at room temperature.

\section{Results and Discussion}

\subsection{Structural Properties}

The influence of deposition temperature on the crystal structure of $\mathrm{ZnO}$ films prepared at different deposition temperatures $350^{\circ} \mathrm{C}, 400^{\circ} \mathrm{C}, 450^{\circ} \mathrm{C}$ and $500^{\circ} \mathrm{C}$ in the range of $2 \theta$ between $30^{\circ}$ and $70^{\circ}$ is illustrated in Fig.(1). The XRD pattern reveals that the $\mathrm{ZnO}$ films are polycrystalline with hexagonal structure. $\mathrm{XRD}$ pattern for film deposited $350^{\circ} \mathrm{C}$ corresponds to $\mathrm{ZnO}$ hexagonal structure 
and the (100), (002), (101), and (110) peaks are appeared. The intensity of (101) peak decrease and (002) peak increase for the film deposited at $400^{\circ} \mathrm{C}$. $\mathrm{ZnO}$ films prepared at $450^{\circ} \mathrm{C}$ have a preferred growth along c-axis, i.e. (002) plane. Other literatures also reported (002) peak as the preferred growth orientation $[11,12]$. As it shown in general the (002) peak increases with the deposition temperature increase. This evolution can be interpreted by the fact that increase in the deposition temperature improve the crystallization of prepared films. $\mathrm{ZnO}$ film prepared at $500^{\circ} \mathrm{C}$ shows a slight decrease of (002) peak intensity. This may be attributed to the increase in re-evaporation rate at higher temperatures which lead to thickness decrease as quantity of materials decrease $[13,14]$.

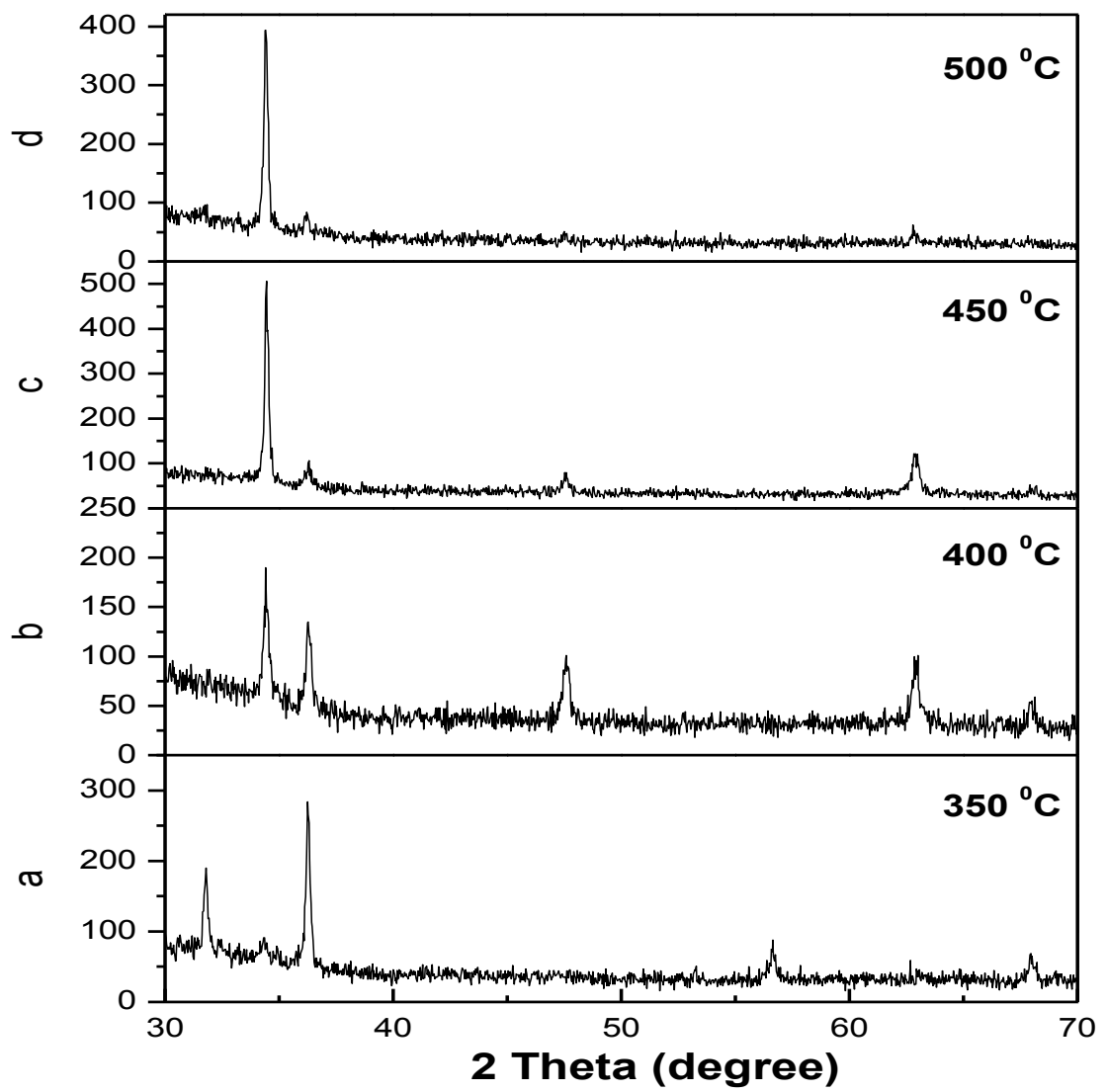

Fig.(1): $\mathrm{XRD}$ pattern of $\mathrm{ZnO}$ films with various deposition temperature (a) $350^{\circ} \mathrm{C}$, (b) $400^{\circ} \mathrm{C}$, (c) $450^{\circ} \mathrm{C}$ and, (d) $500^{\circ} \mathrm{C}$

The lattice constants ' $\mathrm{a}$ ' and ' $\mathrm{b}$ ' of $\mathrm{ZnO}$ films are calculated from planes (002) and (101) using the following equation [15]. 


$$
\frac{1}{d^{2}}=\frac{4}{3}\left(\frac{h^{2}+h k+l^{2}}{a^{2}}\right)+\frac{l^{2}}{c^{2}}
$$

The crystallite size of $\mathrm{ZnO}$ films which are estimated using the well-known Debye-Scherrer formula [15].

$$
D=\frac{0.9 \lambda}{\beta \cos \theta}
$$

where $\beta$ is the observed full width at half maximum intensity (FWHM) of the peak, $\lambda$ is the X-ray wavelength ( $1.54 \AA ; K_{\alpha 1}$ radiation) and $\theta$ is the Bragg's angle. The lattice parameters ( $\mathrm{a}$ and $\mathrm{c}$ ), crystallite size and the films thickness are summarized in Table (1). shows the crystallite size values increase with deposition temperature increase, which may be attributed to the improvement of $\mathrm{ZnO}$ films crystallinity.

The film thickness as a function in the deposition temperature is shown in Table (1). Our results showed that the thickness of $\mathrm{ZnO}$ films decrease with the increase in deposition temperature. This is expected since at high deposition temperature, the sprayed solution vaporizes partially before it reaches to the substrate [16].

Table (1): The lattice parameters, crystallite sizes (D) and the thickness of $\mathrm{ZnO}$ films prepared at various deposition temperature 350, 400, 450 and $500^{\circ} \mathrm{C}$.

\begin{tabular}{|c|c|c|c|c|c|c|}
\hline $\begin{array}{c}\text { Temperature } \\
\left({ }^{\circ} \mathrm{C}\right)\end{array}$ & $\begin{array}{c}\mathrm{a} \\
(\AA)\end{array}$ & $\begin{array}{c}\mathrm{c} \\
(\AA)\end{array}$ & $\mathrm{c} / \mathrm{a}$ & $\begin{array}{c}\text { Crystallite size } \\
\mathrm{D}(\mathrm{nm}) \text { from XRD }\end{array}$ & $\begin{array}{c}\text { Crystallite size } \\
\mathrm{D}(\mathrm{nm}) \text { from SEM }\end{array}$ & $\begin{array}{c}\text { Thickness } \\
(\mathrm{nm})\end{array}$ \\
\hline 350 & 3.245 & 5.2174 & 1.607 & 34.55 & 35.5 & 418.61 \\
\hline 400 & 3.248 & 5.2074 & 1.603 & 50.30 & - & 354.4 \\
\hline 450 & 3.246 & 5.2044 & 1.602 & 65.97 & 65.2 & 347.09 \\
\hline 500 & 3.252 & 5.2028 & 1.599 & 63.42 & 62.9 & 275.68 \\
\hline
\end{tabular}

\subsection{Morphological Characterization:}

Figure (2) shows the SEM micrographs of $\mathrm{ZnO}$ films prepared at various deposition temperatures. As shown in Fig.(3), all films are densely and uniformly covered the substrate. Fig.(3a) shows the surface morphology of $\mathrm{ZnO}$ film prepared at $350^{\circ} \mathrm{C}$ which looks like needles (lenticular like) with a crystallite size of $\sim 35.5 \mathrm{~nm}$ the film. This may be attributed to our film behavior as a polycrystalline material with no preferred orientation. By increasing the deposition temperature to $450^{\circ} \mathrm{C}$ the film has strong (002) 
preferred orientation and grains were found to be rounded shape (columnar) with size $65.2 \mathrm{~nm}$ as show in Fig.(3b). More increasing in deposition temperature up to $500^{\circ} \mathrm{C}$ led to increase in the evaporation rate and the film thickness decrease as quantity of materials decrease, (002) intensity decrease and (101), (103) peaks disappear where the shape of the crystallites of the film were found to be changed with a size ranged between $\sim 62.9 \mathrm{~nm}$ as shown in Fig.(3c) [17].

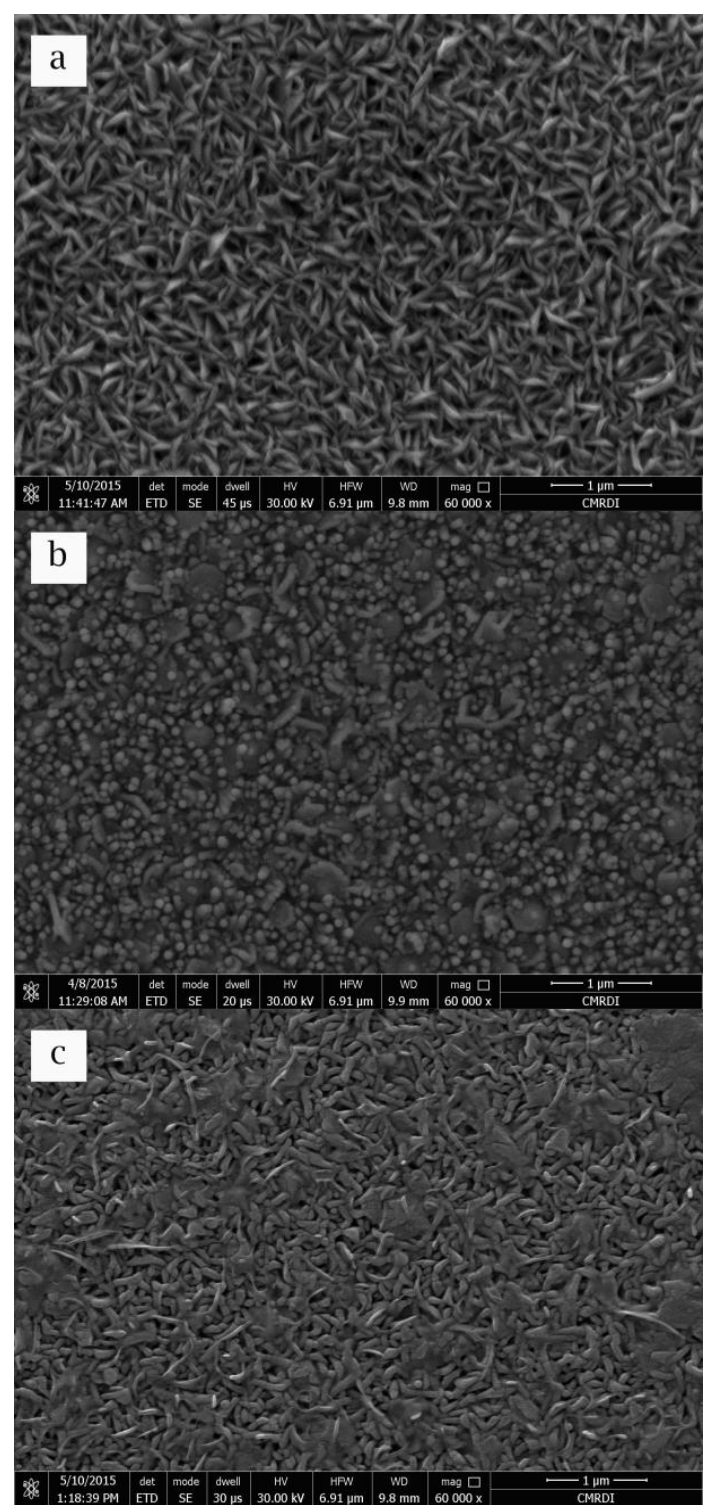

Fig.(2): SEM images for $\mathrm{ZnO}$ films prepared at various deposition temperature (a) $350^{\circ} \mathrm{C}$, (b) $450^{\circ} \mathrm{C}$ and (c) $500^{\circ} \mathrm{C}$. 


\subsection{Optical Characterization:}

Transmission spectra of $\mathrm{ZnO}$ films prepared at various deposition temperatures in the range of (200-2500) nm is shown in Fig.(3). The films are highly transparent up to $90 \%$ in the invisible near infra-red region. The transmissions of the films increase as deposition temperature increase. This may be explained due to the increase in deposition temperature provide thermal energy necessary to form $\mathrm{ZnO}$, therefore the film show better crystallinty and will be more transparent [18].

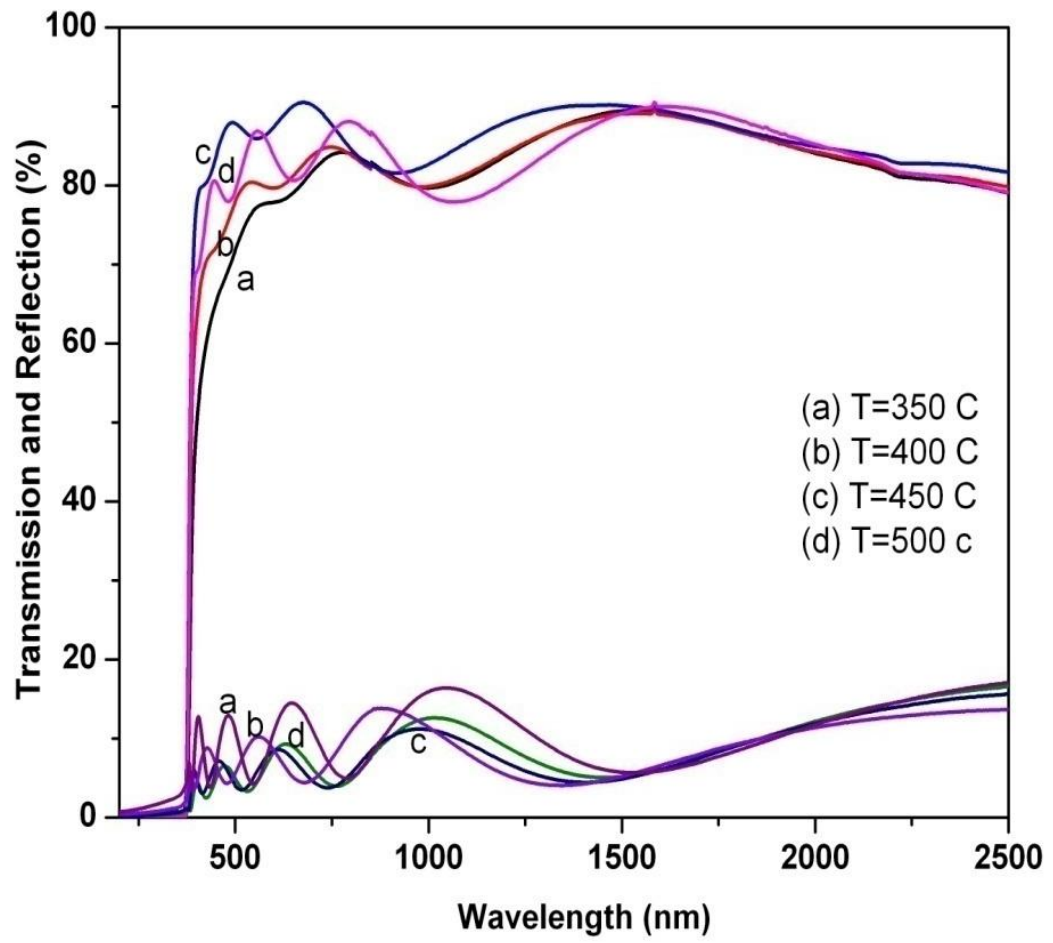

Fig.(3): Transmittance and reflection spectra of $\mathrm{ZnO}$ films prepared at various deposition temperature.

The optical band gap energy was calculated by extrapolation of the linear part of $(\alpha h v)^{2}$ versus photon energy (hv) to $(\alpha h v)^{2}=0$, as illustrated in Fig.(4). optical band gap of $\mathrm{ZnO}$ films are summarized in Table (2).

Table (2): The optical band gap energy of $\mathrm{ZnO}$ thin films deposited with various deposition temperatures.

\begin{tabular}{|l|c|c|c|c|c|}
\hline deposition temperature $\left({ }^{\circ} \mathrm{C}\right)$ & 350 & 400 & 450 & 500 & 350 \\
\hline Optical band gap $(\mathrm{eV})$ & 3.28 & 3.28 & 3.27 & 3.29 & 3.28 \\
\hline
\end{tabular}



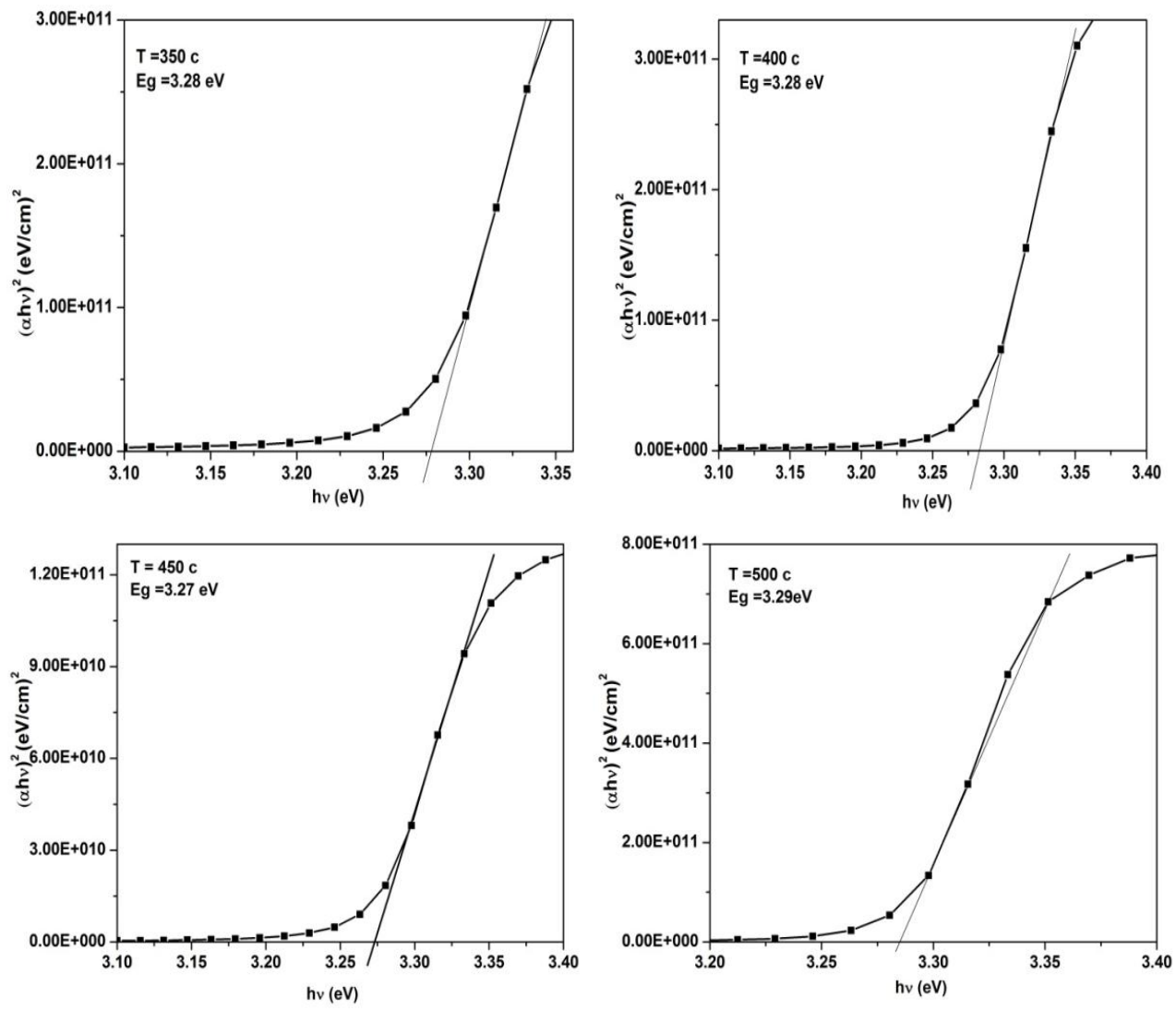

Fig .(4): ( $\alpha$ hv) 2 versus (hv) spectra for $\mathrm{ZnO}$ films at various deposition temperature $350,400,450$ and $500^{\circ} \mathrm{C}$.

The calculated optical band gap of $\mathrm{ZnO}$ films are ranged between 3.27 and $3.29 \mathrm{eV}$ which shows no significant change in band gap energies with deposition temperature. These values of optical band gap are in good agreement with other reports [19, 20,21].

\subsection{Electrical Characterization:}

Hall-effect measurements were performed in order to investigate the effect of deposition temperature on the electrical properties of $\mathrm{ZnO}$ thin films. The measured values of resistivity, carrier concentration, carrier mobility and carrier type are shown in Table (3). 
Table (3): Electrical measurements of $\mathrm{ZnO}$ thin films deposited with various Substrate Temperature.

\begin{tabular}{|c|c|c|c|c|c|}
\hline $\begin{array}{c}\text { Substrate } \\
\text { Temperature }\left({ }^{\circ} \mathrm{C}\right)\end{array}$ & $\begin{array}{c}\text { Resistance } \\
(\Omega)\end{array}$ & $\begin{array}{c}\text { Resistivity } \\
(\Omega . \mathrm{cm})\end{array}$ & $\begin{array}{c}\text { Carrier } \\
\text { concentration } \\
\left(\mathrm{cm}^{-3}\right)\end{array}$ & $\begin{array}{c}\text { Mobility } \\
\left(\mathrm{cm}^{2} / \mathrm{Vs}\right)\end{array}$ & $\begin{array}{c}\text { Conductivity } \\
\text { type }\end{array}$ \\
\hline 350 & $6.46 \times 10^{5}$ & 123 & $1.60 \times 10^{16}$ & 1.11 & $\mathrm{n}$ \\
\hline 400 & $1.97 \times 10^{5}$ & 31.6 & $1.78 \times 10^{17}$ & 3.19 & $\mathrm{n}$ \\
\hline 450 & $7.24 \times 10^{3}$ & 1.14 & $3.3 \times 10^{17}$ & 16.6 & $\mathrm{n}$ \\
\hline 500 & $4.57 \times 10^{4}$ & 5.71 & $1.97 \times 10^{17}$ & 15.56 & $\mathrm{n}$ \\
\hline
\end{tabular}

From Table (3) it could be find that the resistivity of all sprayed $\mathrm{ZnO}$ films is ranging between $123 \Omega \mathrm{cm}$ and $1.14 \Omega \mathrm{cm}$. The dependence of resistivity on deposition temperature is shown in Fig.(5) the minimum value of resistivity of about $1.14 \Omega \mathrm{cm}$ has been obtained at $450^{\circ} \mathrm{C}$ deposition temperature. The improvement of crystallinty of $\mathrm{ZnO}$ film prepared at $450^{\circ} \mathrm{C}$ deposition temperature leads to reduce the resistivity of this film with respect to $\mathrm{ZnO}$ films prepared at $350^{\circ} \mathrm{C}$ and $400^{\circ} \mathrm{C}$ substrate temperatures. This resistivity behavior observed in our films is also reported by Fiddes et al., Kaid and Ashour [22, 23]. However for $\mathrm{ZnO}$ film prepared at $500^{\circ} \mathrm{C}$ substrate temperature, the resistivity showed slightly increasing compared to films prepared at $450 \mathrm{C}$. This may be attributed to the surface effect as it shown in Fig.(2c). where the surface defects, in the sample prepared at $500^{\circ} \mathrm{C}$, act as scattering centers which results in the formation of trapping states capable of trapping carriers and ,thereby, immobilizing them. This process reduces the number of free carriers available for electrical conduction. Also, after trapping the mobile carriers, the traps become electrically charged, creating a potential energy barrier, which prevent the motion of carriers from one crystallite to another, reducing their mobility [9].

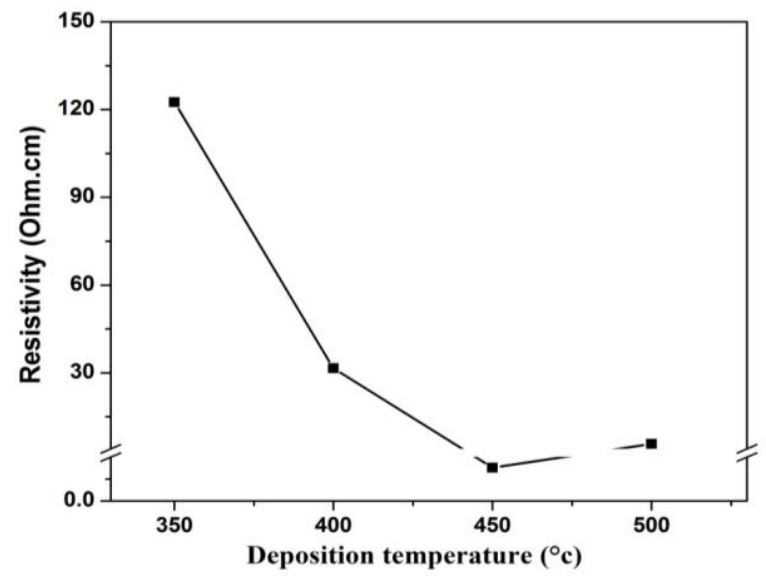

Fig.(5): Resistivity of $\mathrm{ZnO}$ films prepared at various deposition temperature. 


\section{Conclusion:}

In this work we studied the effect of deposition temperature on the structure, morphological, optical and electrical properties of $\mathrm{ZnO}$ thin films. X-ray diffraction patterns reveal that the films are polycrystalline with hexagonal structure. As the deposition temperature increase the intensity of the (002) peak increases. The SEM micrographs show that all films are densely and uniformly covered the crystallites shape of the films was changed as deposition temperature increase. The optical measurements have shown an increase in the transmission (T) \% with deposition temperature increase up to $90 \%$. The film's resistivity decreases with the increase in deposition temperature up to a value of $1.14 \Omega \mathrm{cm}$ and charges mobility $16.6 \mathrm{~cm}^{2} / \mathrm{Vs}$ for $\mathrm{ZnO}$ film deposited at $450^{\circ} \mathrm{C}$.

\section{References}

1. S .M.Rozati, Sh. Akesteh, Materials Characterization, 58, 319 (2007).

2. H. Zhou, D. Yi, Z. Yu, L. Xiao, J. Li, Thin Solid Films, 515, 6909 (2007).

3. P.Nunes, E.Fortunato, R.Martins, Inter. J. Inorg. Mater, 3, 1125 (2001).

4. Z. Xingwen, L.Yongqiang, L.Ye, L.Yingwei, X.Yiben, Vacuum, 81, 502 (2006).

5. S. Fay, U. Kroll, C. Bucher, E. Vallat-Sauvain, A. Shah, Sol. Energy Mater. Sol. Cells, 86, 385 (2005).

6. R. Ghosh, G.K. Paul, D. Basak, Mater. Res. Bull., 40, 1905 (2005).

7. Mihaela, G.G. Rusu, Sylvie Dabos-Seignon, Mihaela Rusu, Appl. Surf. Sci. 254, 4179 (2008).

8. D. F. Paraguay, L.W. Estrada, D.R. Acosta, M.E. Andrade, M. Yoshida, Thin Solid Films, 350, 192 (1999).

9. T. Prasada Rao, M.C. Santhoshkumar, Appl. Surf. Sci., 255, 4579 (2009).

10. Jin-Hong Lee, Byung-Ok Park, Materials Science and Engineering. B 106, 242 (2004).

11. F. Zahedi, R.S. Dariani, Thin Solid Films, 520, 2132 (2012).

12. P. Singh, A. Kumar, Deepak, D. Kaur, Journal of Crystal Growth, 306, 303 (2007).

13. JL. Van Heerden, R. Swanepoel, Thin Solid Films, 299, 72 (1997).

14. M. Penza, MF. De Riccardis, L. Mirenghi, MA. Tagliente, E.Verona, Thin Solid Films, 259, 154 (1995).

15. B.D. Cullity, S.R. Stock, Elements of X-Ray Diffraction, Third Ed, Prentice-Hall, New York, (2001) 99.

16. G.L. Mar, P.Y. Timbrell, R.N. Lamb, Chemistry of Materials, 7, 1890 (1995). 
17. Jae-Sung Hur, Samseok Jang, Donghwan Kim and Dongjin Byun, Journal of the Korean Physical Society, 53, 3033 ( 2008).

18. A. Zaier, F.OumElaz, F.Lakfif, A.Kabir, S.Boudjadar, M.S.Aida, Materials Science in Semiconductor Processing, 12, 207 (2009).

19. F. Zahedi, R.S.Dariani, S.M.Rozati, Materials Science in Semiconductor Processing, 16, 245 (2013).

20. L. Hadjeris, L. Herissi, M.B. Assouar, T. Easwarakhanthan, J. Bougdira, N. Attaf, M.S. Aida, Semiconductor Science and Tech nology, 24, 035006 (2009).

21. A. Mosbah, A. Moustaghfir, S. Abed, N. Bouhssira, M.S. Aida, E. Tomasella, M. Jacquet, Surface and Coatings Technology, 200, 293 (2005).

22. Fiddes AJC, Durose K, Brinkman AW, Woods J, Coates b PD, Banister AJ.J Cryst Growth, 159, 210 (1996).

23. MA. Kaid, A. Ashour, Appl Surf Sci., 253, 3029 (2007). 